\title{
Consenso como sinécdoque y consenso como signo. Una crítica a la concepción rortyana de la verdad, la justificación y el consenso ${ }^{1}$
}

\section{(Consensus as a synecdoche and consensus as a sign. A critique of Rorty's conception of truth, justification, and consensus)}

\author{
Óscar L. GONZÁLEZ-CASTÁN
}

Recibido: 7 de octubre de 2013

Aceptado: 26 de noviembre de 2013

\section{Resumen}

En este ensayo propongo un modelo teórico para comprender el significado y alcance de los acuerdos racionales a partir de una concepción determinada de las relaciones entre justificación y verdad. Desde este modelo, al que denomino "acuerdo como signo", se puede sostener que no todo consenso racional que surge dentro de una comunidad humana, incluidas las científicas, tiene por qué remitir única y exclusivamente a las creencias de ese grupo social y a sus modos internos de justificarlas sin que ellas supongan nunca una ventana abierta al mundo, como sostiene sin asomo de dudas el etnocentrismo de Rorty. Frente al modelo propuesto y valorado desde él, el modelo que sostiene Rorty supone un caso de sinécdoque.

Palabras clave: argumentación, verdad, justificación, falibilismo, esperanza racional.

\footnotetext{
1 Quiero dar las gracias a los evaluadores anónimos de Revista de Filosofía por los valiosos comentarios que hicieron de una versión previa de este trabajo. Los problemas que seguirán existiendo son, sin embargo, responsabilidad únicamente mía.

Este trabajo ha sido posible gracias al Proyecto de Investigación "Normatividad y Praxis. El debate actual después de Wittgenstein" (FFI2010-15975) del Plan Nacional I+D+i. del Ministerio de Ciencia e Innovación.
} 


\begin{abstract}
In this essay I shall propose a theoretical model that will help us to understand the meaning and scope of rational agreements. I build this model from a previous conception of the relationship between truth and justification. With this model at hand, that I shall call "agreement as a sign", it is possible to asses Rorty's ethnocentric claim according to which any rational agreement that a human community could reach, included scientific communities, can only refer to its idiosyncratic beliefs and to its internal ways of justifying them without reference to reality. Against the background of the "agreement as a sign" model, Rorty's model of agreements can be seen as a case of synecdoche.
\end{abstract}

Keywords: Argumentation, truth, justification, fallibilism, rational hope.

\title{
1. Rorty: Consenso, verdad y justificación
}

A lo largo de la discusión contemporánea acerca de las relaciones entre el significado de los consensos racionales, la justificación y la verdad, el pensamiento de Richard Rorty se ha presentado otra vez como un revulsivo porque ha revisado a la baja la pretensión de que los consensos alcanzados mediante justificaciones argumentadas racionalmente se puedan interpretar como síntomas de alguna clase de afinidad entre ellos y la verdad, es decir, como signos indicativos de algún tipo de conexión epistémica entre el ser humano y un mundo que es, sin embargo, ontológica y causalmente independiente de las prácticas y teorías que proponemos sobre él2. Pasaré a exponer concisamente los motivos fundamentales que han llevado a Rorty a sostener tal desvinculación radical entre los consensos alcanzados mediante justificaciones racionales y la verdad para después proponer un modelo alternativo desde el que criticar su caracterización de los acuerdos racionales.

Varias son las razones que, conjugadas, llevan a Rorty a sostener que no existe relación alguna entre los consensos alcanzados por medio de justificaciones racionales y la verdad en ningún área de la actividad humana, incluida la científica. En primer lugar, aparece la idea central de su contextualismo según la cual toda indagación es interpretación y recontextualización de creencias de tal modo que no es posible realizar dicotómicamente la distinción esquema-contenido ${ }^{3}$. Que toda indagación es interpretación significa fundamentalmente que el fin de la indagación

\footnotetext{
2 Rorty sostiene algunas tesis de sabor claramente realista. La fundamental es que el pragmatista postkuhniano es coherentista pero no idealista porque cree, "tanto como el realista, que hay objetos causalmente independientes de las creencias y deseos humanos" (Rorty (1991c), pp. 101).

3 Rorty (1991c), (1998), p.87 y p.91.
} 
racional no es nunca la verdad. Pretender que lo sea es una pura quimera sin mayor fundamento. La razón profunda de esta idea estriba en que pretender haber alcanzado la verdad implicaría que, en nuestros intentos de descripción del mundo, hemos sido capaces de sustraer de ellos la parte que inevitablemente proporcionan nuestros vocabularios y nuestras tradiciones y esquemas de pensamiento para, mediante esta operación de resta, quedarnos únicamente con la parte que el mundo aporta, que sería la única con auténtico contenido cognitivo ${ }^{4}$. Si consiguiéramos realizar adecuadamente tal ejercicio purificador de substracción podríamos tener en nuestras manos un conjunto reducido de auténticas descripciones en las que el ser humano no ha puesto nada de su cosecha, en las que se ha convertido en un espejo neutral del mundo y de sus esencias. La verdad coincidiría con este pequeño reducto de descripciones verdaderas, asépticas, libres de todo contagio humano ${ }^{5}$. Pero tal análisis factorial, de separación de partes, nos está vedado entre otras razones porque no hay ningún método, ni científico ni de otro tipo, que pueda rendir semejante separación, tal y como desearía el realista 6 . Por este motivo, nuestras descripciones son interpretativas sin que sea posible leer en tal expresión oxímoron alguno.

Dado el carácter interpretativo de nuestras descripciones, la indagación racional del mundo no puede consistir en la búsqueda neutral de la verdad 7 . Frente al realismo metafísico, el mundo para nosotros siempre será un mundo en mezcolanza con los sistemas culturales y sociales de creencias que heredamos y que nos constituyen. En esta tesis solo hay que tener cuidado con la idea, que puede sugerir engañosamente esta forma de hablar, de que hay un mundo-en-sí pero que, dadas las limitaciones humanas, no podemos conocerlo porque, en virtud del tipo de contacto cognitivo que tenemos con él, le adherimos inevitablemente las interpretaciones distorsionadoras que proporciona en toda ocasión el hecho de vivir siempre en una tradición cultural previa que aportará, como diría un heideggeriano, un haber previo de conceptos y juicios de los cuales nunca podemos zafarnos completamente. Pero esta interpretación convertiría a Rorty en un escéptico agnóstico de cuño kantiano, una postura filosófica que siempre ha rehuido. Lo que Rorty ha defendido más bien es un anti-esencialismo según el cual el mundo no tiene ningún en-sí cuya estructura e índole tengamos que investigar y que reflejar representacionalmente con nuestras creencias8. Las "cosas" no tienen ninguna esencia o naturaleza y, por lo tanto, no hay ningún mundo-en-sí que esté poblado por estas esencias y por los objetos que las ejemplifican. Lo principal que debemos pedir a nuestras creencias es que nos permitan desenvolvernos cada vez mejor en el mundo cuando lidiamos práctica-

\footnotetext{
4 Rorty (1995), p. 295, (1998), p.87.

5 Rorty (1993), p. 443.

6 Rorty (1991d), p. 142.

7 Rorty (1995).

8 Rorty (1991c), p. 96.
} 
mente con él en todos los órdenes, desde el laboratorio hasta la política. Al fin y al cabo, este filósofo pragmatista mantiene una descripción naturalista de los seres humanos en tanto que organismos que desarrollan herramientas con el fin de adaptarse a su entorno y satisfacer sus variadas necesidades, siendo el lenguaje y las creencias que formulamos por su mediación dos de estas herramientas fundamentales.

Este naturalismo darwinista genérico es complementado por Rorty con otro elemento naturalista más específico según el cual se nos invita a concebir al ser humano como un sistema computacional. Este segundo elemento naturalista, continuación del primero, le sirve a Rorty como comodín para intentar evitar el problema que surgiría de la necesidad de hacer compatible la tesis de que hay un mundo de objetos causalmente independiente de nuestras creencias y deseos con la idea de un mundo antiesencialista. El problema estribaría en que si hay estos objetos causalmente independientes de nosotros entonces su influencia causal se debe, muy probablemente, a que tienen las propiedades que tienen, es decir, se debe a su esencia o, al menos, a su estructura. La respuesta forzada de Rorty a esta dificultad es sostener que la realidad es tan solo un foco de fuerzas causales que ejerce su influencia sobre nosotros pero que no dice nada a menos que estemos programados de ciertas maneras. "El mundo no habla. Solamente nosotros hablamos. El mundo puede, una vez que nos hemos programado a nosotros mismos con un lenguaje, causar que sostengamos determinadas creencias" 9 . Una forma de resumir esta tesis es diciendo que en Rorty el mundo tiene un papel causal pero no epistémico en la formación de creencias.

Estas tesis contextualistas y anti-esencialistas se entreveran en la filosofía de Rorty con la idea del coherentismo social de tipo etnocéntrico. Sin embargo, hay que separar el coherentismo social del giro etnocéntrico que le da Rorty. El coherentismo social es, creo yo, algo perfectamente asumible. Los grupos humanos se encuentran tarde o temprano, en mayor o menor medida, en el brete de tener que incorporar y asimilar nuevas creencias que les obligan a emprender una labor de reacomodación y reestructuración del sistema de creencias del que partían y con el que se enfrentaban a la novedad para darle cabida. Si es posible, esta labor se lleva a cabo al unísono o, si no, hay que intentar que sea de maneras ampliamente consensuadas. El tinte diferenciador que añade el etnocentrismo a este coherentismo social es que la labor de tejer nuevas creencias en la urdimbre y la trama de las ya preexistentes no debe ser interpretada en ningún caso como el intento esperanzador de lanzar mejor un anzuelo a la realidad-en-sí, a la objetividad, a la esencia de las cosas, a través de los procedimientos consensuados de justificación de creencias, siempre revisables y mejorables, pero ya mejorados de hecho históricamente, que se han usado para aceptar e incorporar las nuevas creencias. El etnocentrismo y el contextualismo se dan la mano porque nunca podemos liberarnos de los contextos

\footnotetext{
9 Rorty (1989), p. 6.
} 
de justificación que constituyen a los distintos grupos humanos a través de los cuales estos sopesan racionalmente la pertinencia de la nueva creencia y la manera de integrarla en el sustrato de las que la precedieron. Los sistemas de creencias y los métodos de justificación de creencias son locales, internos, históricos, en una palabra, contingentes, respecto de los grupos sociales. La justificación, como la racionalidad, son siempre internas al sistema de creencias y, por tanto, sus resultados -las creencias justificadas- no pueden tener, ni aspirar a tener en ningún caso, validez universal, una validez independiente del contexto etnocéntrico contingente del que surgieron.

Una vez asentados el contextualismo y el coherentismo etnocéntrico respecto de la justificación, el individuo y la comunidad etnocéntrica a la que aquel pertenece simplemente tienden a modificar y, en general, a expandir el ámbito de sus creencias usando sus modos de justificarlas sin alcanzar jamás la objetividad, ni de estar siquiera en vías de lograrla por medio alguno, a pesar de que esta expansión se realice, de una manera débilmente idealizada, ante públicos cada vez más amplios, más numerosos y más diversos, aunque no sean todos los públicos imaginables posibles ${ }^{10}$. La lucha por la verdad y la objetividad cede el paso, de una manera dicotómica excluyente muy poco pragmatista, a la solidaridad, al intento de decir un "nosotros" que sea cada vez más amplio, que incluya, de maneras no violentas y democráticas, a públicos cada vez más dispares y distantes tanto espacial como temporalmente ${ }^{11}$. Los acuerdos no son nunca indicativos, ni directa ni indirectamente, de la universalidad y la verdad en un sentido no etnocéntrico. Su alcance es, por tanto, siempre limitado y local tanto por lo que se refiere al contenido de las creencias que lo constituyen, como a las formas de justificación lógicas, internas, que igualmente lo conforman e identifican.

Por lo que se refiere precisamente a los contenidos de nuestros sistemas de creencias y a las normas temporales de justificación que han respaldado tales contenidos y, a su vez, son respaldadas por ellos, Rorty defiende una actitud abiertamente falibilista. Este filósofo considera que la palabra "verdad" tiene un uso aproblemático si simplemente aparece de forma cautelar, admonitoria o precautoria (cautionary use) para advertirnos que un grupo humano, sea el que sea, puede consensuar que un juicio o proposición está suficientemente justificado y, sin embargo, no ser verdad 12. Para él, este uso cautelar del término "verdad" es el único verdaderamente ineliminable y, por lo tanto, el más importante respecto de los otros dos que tam-

\footnotetext{
10 Rorty (2000a), p.1.

11 Rorty (1991a), p.21. Considero que Rorty, en este texto, nos insta a decidirnos por la objetividad o por la solidaridad de formas que, dada su descripción ad hoc, se excluyen entre sí cuando, como argumentaré posteriormente, no hace falta aceptar los términos en los que Rorty presenta la dicotomía porque, en realidad, quien acepta uno de sus polos acepta también el otro de una forma indisoluble.

12 Rorty (1991d), p.128; (2000a), p.4.
} 
bién reconoce, a saber, el uso desentrecomillador (disquotational) y el uso como aval o comendatorio (endorsing) ${ }^{13}$. Como dice McDowell, el uso cautelar del término "verdad" es considerado por Rorty como un sano tener puesto un pie atrás que evite que uno se convierta en un parroquiano de sus propias teorías y juicios y se considere, para expresarlo como diría Carlos Pereda, en un representante dogmático de "la razón arrogante" 14 .

Rorty considera que este uso cautelar está siempre justificado hayamos llegado hasta donde hayamos llegado en nuestras investigaciones, tanto en sus resultados como en sus procedimientos y normas. Tres parecen ser las razones fundamentales para sostener esta tesis. (1) Detenerse en un punto de la investigación y decir "esta teoría es la verdad" es considerar que ninguna audiencia futura bien cualificada va a poder encontrar ninguna objeción justificada en contra de la creencia o teoría propuesta15. (2) Esto implicaría que, como no podemos saltar por encima de nuestras mentes y tradiciones para comparar sus contenidos (creencias, teorías, etc.) con el mundo, no podemos contar con criterios que dictaminen la adecuación perfecta de nuestros vocabularios y enunciados al mundo, único momento en el que se podría declarar su verdad ${ }^{16}$. (3) En el caso de que hayamos encontrado las teorías verdaderas, nunca podremos saber que lo hemos hecho. ¿Cómo podemos reconocer que estamos al final de la investigación si no es precisamente saltando por encima de nuestras propias teorías para concluir que ahora, esta teoría precisamente, es la verdadera, la que se corresponde con la realidad? ${ }^{17}$ Podemos saber, por tanto, cuándo nuestras teorías están justificadas de acuerdo con nuestros estándares etnocéntricos y revisables de justificación racional pero no cuándo son verdaderas. Y como no podemos saber si hemos alcanzado la verdad, no tiene sentido tener a la verdad como objetivo o fin de la investigación ${ }^{18}$.

Como muy bien señala Bilgrami, Rorty, siguiendo a Putnam, considera que la expresión cautelar "... y no ser verdad" indica siempre que no es una cuestión en absoluto trivial preguntar si un juicio o teoría que se considera bien justificado es, sin embargo, verdadero ${ }^{19}$. Que no sea trivial la pregunta indica la distancia que hay entre verdad y justificación. Esta distancia es interpretada por Rorty no, como hace Davidson, en el sentido de que la verdad sea objetiva porque no podemos decir qué creencias son verdaderas aunque algunas lo serán y lo serán independientemente de que estén justificadas por toda nuestra evidencia disponible, siempre limitada 20 .

\footnotetext{
13 Rorty (1991d), p.128, (2000a), p.4.

14 McDowell (2000), p.115, Pereda (1999).

15 Rorty (2000a), p.6.

16 Rorty (1998), p.86.

17 Rorty (1991d), p.131.

18 Rorty (2000a), p.2.

19 Bilgrami (2000), p.244.

20 Davidson (2000), p.67.
} 
Rorty sostiene más bien que la distancia entre justificación y verdad aparece cuando nos damos cuenta de que por muy bien justificada que esté una creencia ante las audiencias relevantes y competentes en un momento determinado, pueden aparecer en el futuro hechos nuevos y nuevos grupos humanos, "audiencias más imaginativas", para las cuales la creencia no esté en absoluto bien justificada. La verdad se la representa Rorty no solo como ese momento en el que hemos logrado hacer el análisis factorial que señalaba antes, sino como coincidiendo con ese momento ideal imposible en el que una justificación no encontrará ninguna apelación posible por generación futura alguna que exija nuevas justificaciones porque las anteriores le parecen insuficientes. Como puede verse, la expresión cautelar “... y no ser verdad" termina significando en Rorty lo mismo que "... y no estar justificada para alguna generación futura competente". Que una proposición o teoría sea verdadera es algo que, en definitiva, no nos incumbe desde un punto de vista pragmático. Preocúpate, dice Rorty, de que las creencias estén bien justificadas ante las audiencias pertinentes y no te preocupes por su relación con la realidad, por su verdad 21 .

\section{La segunda navegación de la filosofía}

De acuerdo con las perspectivas filosóficas pragmatistas que Rorty encarna, los acuerdos no forzados tienen una importancia fundamental como manifestaciones de un talante y de una manera de comprender la argumentación, la verdad y la racionalidad. Hemos visto que a la pregunta de por qué alguien, ya sea un individuo o un grupo social, debería aceptar las creencias y los modos lógicos de justificarlas que una determinada comunidad humana asume, la contestación rortyana es siempre que esto se hace para construir un nosotros más amplio, un consenso más efectivo, solidario y abarcante. La tesis que defenderé es que esta concepción de los consensos es una sinécdoque, es decir, una manera de quedarse con una parte del sentido general y total de los acuerdos que impide ver el alcance real que estos puedan tener respecto de las pretensiones humanas de conocimiento del mundo. Cuando se pierde esta capacidad, estamos ante un claro ejemplo de reduccionismo.

Sin embargo, para poder argumentar bien esta tesis es preciso construir antes, aunque sea en esbozo, una concepción diferente de las relaciones entre justificación y verdad sobre cuyo trasfondo se pueda empezar a entender que lo que Rorty hace respecto del sentido de los acuerdos es recortar innecesariamente una parte de un todo más amplio. Para esta labor quiero encarnar retóricamente en Platón, mediante la exploración de ciertas ramificaciones que tienen algunos textos centrales de su filosofía que no apelan a la transcendencia de la verdad, y en el propio Rorty dos modelos del acuerdo: el acuerdo como signo o indicio y el acuerdo como sinécdo-

\footnotetext{
21 Rorty (2000a), p. 9.
} 
que, respectivamente. Usaré en este contexto el término "signo" en el sentido husserliano de "signo indicativo" (Anzeichen) el cual queda caracterizado en la Primera Investigación Lógica de la siguiente manera: Un objeto o situación es signo indicativo "cuando este algo sirve efectivamente de señal de algo para un ser pensante [...] Ciertos objetos o situaciones objetivas, de cuya existencia alguien tiene conocimiento actual, indican a ese alguien la existencia de ciertos otros objetos o situaciones objetivas -en el sentido de que la convicción de que los primeros existen es vivida por dicho alguien como motivo [...] para la convicción o presunción de que también los segundos existen"22. El hueso fósil es signo indicativo de la existencia de animales prehistóricos. El acuerdo, así argumentaré, es una situación que puede servir racionalmente a una comunidad de seres pensantes como motivo no dogmático, ni fundado en certezas, de que podrían haber hecho una enunciación verdadera y no meramente, aunque también, que han emitido un juicio que tiene una buena justificación de acuerdo con los estándares existentes de validez racional grupales, etnocéntricos, aunque siempre falibles 23 .

Empecemos con la reconstrucción del modelo platónico tal y como se empieza a exponer en Fedón ${ }^{24}$. En este diálogo, Sócrates, en lo que él denomina la "segunda navegación" de la filosofía, narra su autobiografía intelectual, la cual coincide con el camino que va desde la investigación de las cosas en sí mismas mirándolas directamente con nuestra inteligencia a la investigación de las cosas en y a través de los discursos y razonamientos más inconmovibles. Presocrático sería, pues, quien considerara que, al mirar directamente al mundo, este nos diría, en ciertas condiciones, qué discurso es verdadero porque nos forzaría en todo momento a admitir uno y no otros. Frente a estos realistas metafísicos presocráticos, el texto de Fedón propone que nos refugiemos en cierto tipo de discursos y argumentaciones para examinar en ellos "la verdad de los seres". Sin embargo, el fundador de esta segunda singladura de la filosofía no se dejó engañar fácilmente por la metáfora que estaba proponiendo para hacernos creer que hemos comprendido realmente algo, pues dice: "Porque no estoy muy de acuerdo en que el que examina los seres (tà ónta) en los discursos (en lógois) los contemple más en imágenes o representaciones (en eikósi)

\footnotetext{
22 Husserl (1900/1984), p. 31. El subrayado es de Husserl.

23 Se podría argumentar que la discusión que se plantea a continuación, además de detallada, no le importaría mucho a Rorty dado que él estaba más interesado en las consecuencias éticas, políticas o culturales de sus críticas a las nociones epistemológicas tradicionales, como las de verdad o certeza, que en esas nociones por sí mismas. Aunque es cierto que Rorty siempre quiso reflexionar con especial énfasis sobre este tipo de consecuencias prácticas de su filosofía, también es un hecho abrumador que dedicó cientos de páginas a desarrollar y repetir una y otra vez sus críticas a aquellas nociones epistemológicas y a sus consecuencias ontológicas (esencialismo, mundo-en-sí, etc.). Este artículo se centra en el análisis de esta base propedéutica que asienta Rorty. Las consecuencias prácticas de la crítica que desarrollo no caben en los márgenes de un estudio de este estilo.

24 Platón (1986), Fedón 99d-100a; cfr. Platón (1992), Filebo 19c.
} 
que el que los examina en los hechos/las obras/los actos (en érgois). En fin, el caso es que por ahí me lancé, y tomando como criterio el discurso hipotético que juzgo más inconmovible/vigoroso (erōmenéstaton) en cada momento afirmo como verdadero lo que parece concordar con él, tanto por lo que respecta a su causa/fundamento/justificación (perì aitías) como a todas las demás cosas, y lo que no, como no verdadero" 25 .

Ahora bien, el resultado de fijar discursos, de tener creencias robustas bien garantizadas, puede tener al menos dos aspectos. En el primero, más limitado y en ocasiones el único posible, solo se logra convenir negativamente qué creencia o juicio no puede ser tenido ya por verdadero porque se considera que este juicio no está suficientemente garantizado de acuerdo con nuestras normas actuales de justificación, reglas de razonamiento, observaciones y nuevos comportamientos. En el segundo, además de lograr este primer tipo de acuerdo negativo, se consensúa también positivamente qué otro juicio parece estar ahora mejor justificado y es, por tanto, un candidato más ajustado que el anterior a ser verdad, pues este último parece no poder serlo ya más. Analizaré por separado ambas posibilidades y extraeré algunas consecuencias que no han sido contempladas por Rorty.

Que la discusión racional no acaba siempre en un acuerdo en el que se establezca una tesis positiva acerca del problema tratado es uno de los aprendizajes fundamentales que se extraen de los diálogos platónicos del periodo socrático. Estos diálogos terminan muchas veces de una manera abierta y aporética, aunque esto no quiera decir necesariamente que terminen en disenso. En el fondo, en ellos no se ha acordado apenas nada en forma de tesis positiva, aunque la mayoría de los que han participado en la discusión han adquirido conciencia plena de dos cosas. Por una parte, saben que las primeras respuestas confiadas que se ofrecieron de manera supuestamente justificada a la cuestión planteada, siempre dependientes de algunos supuestos y formas de razonamiento, carecen de valor y, por lo tanto, consideran también que se precisa una reorganización en el sistema de creencias que no se sabe muy bien cómo culminar pero que ya ha comenzado porque han eliminado de él algunas creencias anteriores, hipótesis de partida y pruebas aceptadas. Por otra parte, son conscientes, sin embargo, de que no se logra avanzar suficientemente para establecer una solución alternativa bien justificada al problema originario o para detectar claramente nuevos errores en los modos de razonamiento y justificación que sustentaban la creencia ahora desarbolada. En cualquier caso, hay en el élenchos socrático un valiosísimo consenso sobre el "ya no así'. Es la diferencia que se marca enfáticamente entre, por una parte, conocer la verdad y ser sabio y, por otra, conocer lo que no puede ser verdad y tener así la poco valiosa sabiduría humana pero sabiduría al fin y al cabo 26 . Si se quiere decir en términos popperianos, este

25 Platón (1986), Fedón 100a.

26 Platón (1981), Apología 23a. 
es el momento en que se considera que la creencia previa ha sido falsada sin tener todavía ninguna alternativa que la suplante.

La segunda posibilidad planteada es que no solo se determina por consenso qué discurso anterior no puede ser fijado ya más como verosímil, es decir, como candidato a ser un discurso verdadero, aunque fuera así considerado en su momento, sino que se propone uno alternativo para pensar desde él cómo serían las cosas, pues estas no pueden ser según se creían anteriormente. Y en este proceso en el que, a diferencia del caso anterior, se alcanza un resultado positivo se establecen de una sola vez varias cuestiones encadenadas. Primero, un consenso también sobre cuál es el discurso con cuyo soporte no podemos concebir ya más justificadamente las cosas que estamos discutiendo.

Segundo, un consenso sobre cuál es el discurso que ahora tomamos como un signo indicativo más fiable para pensar acerca de cómo es el universo de objetos sobre el que estamos debatiendo racionalmente.

Tercero, la conciencia clara de que a las creencias consensuadas pasadas, si hiciéramos un viaje imaginario de regreso a ellas desde lo que creemos saber ahora justificadamente, habría que haberles añadido en su momento la glosa “... y no ser verdad". Estaban bien justificadas desde lo que se pensaba entonces pero no podían ser verdaderas desde lo que se cree ahora como bien justificado.

Cuarto, una nota precautoria según la cual, de la misma manera que en el pasado se consideraba que había discursos bien fijados pero que ahora no se consideran consensuadamente como candidatos posibles a la verdad porque no podemos justificarlos ya más -hecho que posibilita que entendamos el falibilismo como tesis general sobre el conocimiento humano ${ }^{27}$-, también es conveniente racionalmente considerar que los discursos acordados como firmemente justificados en el momento actual tendrían que ir acompañados de la glosa "...y no ser verdad", si es que queremos extraer algunas consecuencias de nuestra experiencia pasada. Y esto significa simplemente que algunas de nuestras creencias presentes pueden ser falsas (sin saber exactamente cuál es la extensión de estas creencias falsas), pero no significa necesariamente que cualquiera lo pueda ser o que todas lo sean ${ }^{28}$. En este caso, nuestra experiencia del error nos dice únicamente que algunas de nuestras creencias pasadas eran falsas a pesar de haberse consensuado su justificación. Como diría un wittgensteiniano, vivir el error solo es posible sobre un trasfondo de creencias que no se considera, ni se puede considerar, todo él erróneo. Así pues, de la experiencia del error, que afecta siempre de forma limitada a nuestro cuerpo de creencias, y que nos ha llevado a decir que algunas de nuestras creencias pasadas parecían justificadas pero que no pueden ser verdaderas, no se puede deducir que todas nuestras creencias actuales puedan ser falsas, sino solo que algunas lo pueden ser.

27 Cfr. Kalpokas (2005), p. 221.

28 Hurtado (2009), p. 49; Wellmer (2010), p. 315. 
El platonismo propuesto no es, pues, escepticismo, aunque si no se matiza podría equivocarse con alguna de sus múltiples formulaciones, sino un faliblismo peculiar, un falibilismo asimétrico que aclararé enseguida y que desembocará en un agnosticismo matizado.

Quinto, que el cambio desde el discurso pasado que se ha inhabilitado ahora como candidato a la verdad hasta el discurso mantenido en la actualidad implica normalmente un cambio no solo en las cosas que ahora se creen con firmeza, una reorganización, por tanto, en el contenido de nuestro cuerpo de creencias, sino un cambio en los procedimientos lógicos para determinar cuándo un discurso (juicio, creencia o teoría) está bien establecido y, en ocasiones, un cambio también en alguno de los presupuestos mismos de la argumentación que antes se daban por sentados, por "evidentes". Siempre habrá que suponer que el cambio en lo que se considera bien justificado y se presenta ahora como un candidato más robusto a la verdad, por estar más firmemente justificado y afianzado, -candidatura a la que llamaré su "verosimilitud"- está motivado razonadamente por alguna mejora o cambio en nuestros métodos lógicos de justificación de creencias, en sentido amplio, además de por nuevos datos o comportamientos que antes no podíamos tener en cuenta ${ }^{29}$. El modelo platónico, por tanto, no tendría nada que objetar a la afirmación de Peirce según la cual todo paso importante en la ciencia ha sido una lección de lógica porque ha mostrado de alguna manera los defectos en el arte de razonar que se encarnaban en el estado previo de la ciencia, aunque ella misma pueda ser un ejemplo vívido de otros defectos lógicos todavía por detectar y que pueden surgir a la luz de nuevas observaciones y de sus interpretaciones ${ }^{30}$. En cualquier caso, lo que se está proponiendo es la legitimidad de un argumento abductivo del tipo "inferencia a la mejor explicación", aunque no se trate de inferir la verdad de ciertos enunciados, ni siquiera de inferir que sean aproximadamente verdaderos, como mejor explicación del nuevo consenso ${ }^{31}$, sino de inferir la mayor verosimilitud, su mayor afianzamiento, sin descartar en ningún momento su falibilidad 32 .

\footnotetext{
29 Frente a una noción de verdad absoluta, Niiniluoto (1999 y 1987) y Oddie (1986) han defendido la noción de verosimilitud (truthlikeness) por ser más flexible y adecuada a la hora de defender el realismo científico crítico, aunque hablar de este tipo de realismo no es mi objetivo aquí. Sí observaré, sin embargo, que la diferencia fundamental con estos autores es que la noción de verosimilitud, tal y como la iré especificando, no hay que pensarla como indicativa de que existe una medida fiable del acercamiento de una creencia o teoría a la verdad o a la realidad. Saber que algo se acerca a un objeto es saber dónde está y cuál es el objeto al que nos acercamos. Si este objeto al que nos acercamos fuera la verdad, esto querría decir que ya la conocemos.

30 Peirce (1877/1974), p.225.

31 Boyd (1990).

$32 \mathrm{El}$ argumento de Boyd consiste en defender que la mejor forma de explicar la fiabilidad de ciertos principios metodológicos básicos de la investigación científica contemporánea sería mediante una concepción realista (Boyd (1990), p.355). Con ellos se capta mejor la realidad porque rinden creencias "aproximadamente verdaderas" que pueden ser consensuadas por quienes siguen esos métodos.
} 
Como conclusión, pero también para extraer algunas consecuencias importantes de lo que he argumentado, podemos decir que el acuerdo tras la discusión nos permite ir creyendo gradualmente, aunque con todas las limitaciones y precauciones expuestas, si no directamente en el progreso del conocimiento, sí, al menos, en la regresión de nuestro desconocimiento en la forma de un conocimiento progresivo de lo que no podemos considerar como verdad. De esta forma creemos haber picado porciones importantes de la ganga adherida a una posible concepción más ajustada de las cosas por estar más justificada. Sin embargo, no se puede pensar en una regresión del desconocimiento de la forma indicada más que postulando pragmática y retrospectivamente un ser de las cosas, una "realidad-en-sí", como su condición de posibilidad respecto de la cual decimos, precisamente, que la creencia eliminada es inadecuada. La idea de realidad-en-sí se postula, entonces, retroactivamente para dar soporte ontológico y práctico a la idea del error ahora detectado. Lo que posibilita esta postulación pragmática es que la creencia eliminada no solamente es falsa para nosotros por capricho arbitrario, sino porque nos pensamos a nosotros mismos y a nuestra creencia eliminada en relación con ese horizonte indeterminado de sentido que llamamos "realidad". Lo califico como indeterminado porque no condiciona de forma directa contenido alguno y porque no sabemos con certeza qué es adecuado para él aunque sí sepamos, es decir, sí juzgamos con más garantías, qué le resultaría inadecuado. Como puede verse esta postulación la hacemos, además, sin que ello suponga ningún tipo de representacionalismo y sin que, como dice Rorty, estemos proyectando desde lo condicionado a lo incondicionado, de lo relativo a lo absoluto, o presuponiendo un orden natural de las razones 33 .

El sentido en que Rorty hace esta afirmación es que no es legítimo proyectar desde lo que podemos vislumbrar nosotros aquí y ahora como justificado a lo que toda comunidad posible podría llegar a concebir y que debe coincidir con lo que nosotros consideramos justificado. Por el contrario, el conocimiento de lo que no podemos considerar ya más como justificado y, por lo mismo, como verdadero, no es proyectar de lo condicionado a lo incondicionado en este sentido. Es reconocer simplemente que eliminamos creencias de nuestro sistema previo porque los argumentos más fuertes nos impiden adherirlas cognitivamente a la realidad que se postula concomitantemente en la propia eliminación de esas creencias.

Además, esta noción retrospectiva de realidad-en-sí en tanto que horizonte indeterminado de sentido de la argumentación y de sus logros parciales es una condición que permite entender la adhesión constante a nuestras creencias de la cláusula precautoria “... y no ser verdad" y no algo, como piensa Rorty, a lo que debamos ajustarnos o que sirva de término de comparación para establecer una noción de ver-

En definitiva, Boyd trataba de mantener que el éxito metodológico, empírico y predictivo de una teoría apoya la inferencia de que es aproximadamente verdadera.

33 Rorty (1999), p. 24. 
dad como correspondencia o que sea la meta de la investigación o algo con lo que, en definitiva, tengan que converger nuestras teorías en el futuro o que nosotros tengamos que representar. Nosotros introducimos esta cláusula porque ya la hemos hecho efectiva de facto respecto de creencias pasadas sostenidas por nosotros y porque, siendo consecuentes, podemos, de iure, pensar razonablemente y de maneras no arrogantes que algunas audiencias futuras relevantes pueden hacerla también efectiva respecto de algunas de nuestras creencias actuales.

Es cierto, sin embargo, que Rorty no cree que, para explicar el uso precautorio del término "verdad", haya necesidad de postular una realidad en sí. Como hemos visto, para ello bastaría con contraponer audiencias actuales con audiencias futuras. Decimos que una creencia podría no ser verdad en relación con una posible audiencia futura que la descartaría por injustificada. Por tanto, aunque el modelo que estoy proponiendo renuncie a la idea de verdad como meta de la indagación, todavía retendría una noción que, a los ojos de Rorty, constituiría un residuo de (mala) metafísica.

A este argumento tengo que contraponer dos observaciones. La primera es que la introducción de la noción de realidad-en-sí en el sentido retrospectivo señalado no tiene nada de (mala) metafísica ni, a decir verdad, de metafísica alguna. No hay nada metafísico en decir que eliminamos creencias porque no las podemos respaldar cognitivamente $y$, por tanto, no podemos adherirlas razonablemente a la idea de realidad-en-sí. La segunda es que Rorty se basa en el fondo en la validez incondicional del argumento de la meta-inducción pesimista: siempre puede haber una audiencia futura que encuentre injustificada nuestra creencia. Pero, como argumentaré, esto no tiene por qué ser así.

\section{Lo que proponemos como verdad: alcance y limitaciones}

Más allá de estas primeras consideraciones, ¿qué sucede en el segundo caso, es decir, cuando se propone una creencia o teoría como candidata más plausible a ser verdad en sustitución de otra previa? Platón dice que las nuevas afirmaciones que sostenemos pueden estar "unidas y atadas, aunque sea un poco rudo decirlo así, con razonamientos de hierro y de acero, por lo menos, según se puede pensar"34. Para rechazar semejantes afirmaciones haría falta desbaratar esos robustos razonamientos que las sostienen y toda la evidencia justificativa, del tipo que sea, a la que se apela para afianzarlas. Mientras que esto no suceda podemos establecer que las cosas son así en la realidad, a pesar de la sombra amenazante del falibilismo respecto de algunas cosas que creemos ahora. Tenemos certeza de ellas, aunque no las

34 Platón (1983), Gorgias 509a; cursiva mía. 
dotemos de incorregibilidad 35 . Esta actitud, sin embargo, no es incompatible con sostener que, a pesar de que nuestras creencias, según consideramos y pensamos, están bien atadas a sus fundamentos racionales, a sus modos lógicos de justificación, sin embargo, no sabemos con plena certeza cómo son las cosas, no sabemos plenamente si estas creencias son verdaderas o no ${ }^{36}$.

Sin embargo, la forma de pensar que enmarcan estos textos platónicos puede parecer extraña y hasta contradictoria. ¿Cómo es posible que podamos establecer con suficiente confianza pragmática que las cosas pueden ser más razonablemente como las constituyen los argumentos de hierro y acero que hemos consensuado y, sin embargo, que no sepamos con plena certeza si las cosas son de verdad así porque no sabemos con evidencia si nuestras creencias son verdaderas o falsas? Todo esto a pesar de haber eliminado creencias justificadamente y haber adquirido el compromiso de que lo hacemos porque la realidad no se deja pensar adecuadamente con ellas. Creo que la clave de la respuesta es que no saber con certeza si una creencia es o no verdadera no excluye necesariamente y por principio, sobre la base de que nos sentimos ahora más confiados en nuestros métodos de investigación y justificación, que la creencia sea verdadera.

De estas ideas de Gorgias hay que extraer dos tesis que constituyen el núcleo de la argumentación una vez que hemos llegado a este punto. La primera es que es posible sostener que la nueva teoría propuesta no simplemente reemplaza a la anterior sino que la reemplaza racionalmente motivada, lo cual incrementa su verosimilitud, sus credenciales para ser verdadera, sus pretensiones de validez transcontextual, fuera del propio grupo de referencia ${ }^{37}$. A pesar de ello, no hay seguridad completa de que las nuevas creencias no puedan ser falsas, pero hay más probabilidades de que no lo sean dado que nuestros métodos y modelos teóricos nos parecen mejores. La segunda es que, en estas condiciones, tiene sentido y es racional considerar el nuevo conjunto de creencias como verdadero. Argumentaré estas dos tesis por separado y mostraré su sentido para el problema general de la verdad. Considero, además, que estas tesis constituyen el lugar epistemológico peculiar que habita el ser humano.

\subsection{Falibilismo asimétrico y verosimilitud}

Para comenzar a argumentar la primera de las dos tesis mencionadas, me voy a fijar ahora en lo que las dos situaciones descritas anteriormente tienen en común, a saber, que en ellas se cree haber detectado un conjunto limitado de creencias pre-

\footnotetext{
35 Levi (1991), p. 3.

36 Platón (1983), Gorgias 509a.

37 Habermas (1999), p. 35.
} 
vias que ahora son injustificables y que, por lo mismo, no son consideradas ya más como candidatas plausibles a ser creencias verdaderas. Sin embargo, esta no es la única idea que puede extraerse de los diálogos de Platón. Además, es también característico de ellos el hecho de que, en muchas ocasiones, no se vuelvan a considerar como justificadas las creencias que acaban de ser abandonadas, aunque algunos interlocutores por querencia, costumbre, prejuicio malsano o interés, deseen volver a ellas pertinazmente. La moraleja de esta situación, sin duda un tanto idealizada, es que los interlocutores consideran que no cometen conscientemente ningún error de principio cuando abandonan sus creencias previas en aras de otras que, a primera vista, les pueden parecer incluso más descabellas y menos comprensibles, aunque mejor justificadas.

¿Qué importancia tiene esta idea para el problema que nos ocupa? Sobre todo nos permite establecer que la tesis del falibilismo tiene una fuerza y verosimilitud asimétrica cuando se dirige o se aplica a nuestras creencias presentes y cuando se dirige a nuestras creencias abandonadas. La fuerza racional del falibilismo en el primer caso es mayor que en el segundo. En definitiva, los diálogos platónicos sugieren que puede haber un falibilismo respecto de nuestras teorías presentes pero no puede haberlo sistemáticamente, y en el mismo grado, sobre el abandono de nuestras teorías pasadas. Pero no solo Platón cree esto. En este punto me parece que, por ejemplo, Charles Taylor tiene razón cuando le indica a Rorty que "algunos puntos de vista son irrecuperables; nadie puede siquiera llegar a conseguir buenas razones para volver a creer en ellos otra vez"38. El contexto de esta afirmación de Taylor es recordarle a Rorty que el abandono de ciertas teorías parece, efectivamente, definitivo y que, por lo tanto, no es cierto que no se puedan arbitrar o reconstruir racionalmente las diferencias entre distintos juegos de lenguaje -el ejemplo de Taylor es Aristóteles frente Galileo y Newton. No nos equivocamos sistemáticamente cuando abandonamos ciertas teorías, aunque las nuevas puedan estar equivocadas en ciertos respectos. La reforma de nuestros métodos lógicos de justificación junto con, quizá también, las nuevas hipótesis, supuestos, preguntas, planteamientos y hechos sacados a la luz, hacen que, de una manera justificada, no consideremos la anterior teoría como posible candidata a la verdad. La historia de algunas disciplinas, como la historia de la ciencia, afianza esta tesis. Nadie competente considera que haya que volver a Ptolomeo y a los sistemas ptolemaicos para hablar justificadamente de la estructura y dinámica del sistema planetario solar. Podemos decir también que si no hubiera tal grado de implausibilidad sobre el falibilismo aplicado a nuestro abandono de concepciones pasadas, no podría haber tampoco confianza en que hemos cometido un error porque entonces la creencia pasada nunca podría haber sido declarada falsa con mínimas garantías. Tan importante como tener una

38 Taylor (1990), p. 262. 
teoría sobre el sentido de la verdad y de la justificación es tener una teoría sobre el sentido del error. Este falibilismo asimétrico permite tal teoría.

Aunque este falibilismo asimétrico pueda parecer inofensivo, lo cierto es que es una de las grietas por las que craquea en múltiples direcciones el pensamiento pragmatista de Rorty sobre estas cuestiones. La fuerza menor del falibilismo cuando se aplica al abandono de nuestras creencias pasadas tiene repercusiones en la mayor verosimilitud, en tanto que mejores candidatas a la verdad, de las creencias presentes cuando estas se han obtenido gracias a la reforma mejorada de nuestros métodos lógicos, de justificación, empíricos y de otras clases. Como ha puesto de manifiesto el texto de Gorgias citado anteriormente, los participantes en la discusión no solo abandonan creencias pasadas y están justificados cuando consideran que no hay vuelta atrás; no solo reajustan sus métodos de prueba y razonamiento y su sistema de creencias en función de ciertos cambios que parecen imponerse gradualmente, sino que, en función de la argumentación general que tienen ante su consideración racional, las nuevas creencias aparecen como más robustas, menos proclives a ser refutadas que las anteriores. Ellos, al menos, son ahora menos capaces de abandonarlas justificadamente. Y esto, como también se dice en Gorgias, les motiva racionalmente a considerar las nuevas creencias como verdaderas, por ser más verosímiles, aunque no tengan evidencia plena de su verdad ni de su capacidad "representativa" y, por tanto, de su acercamiento a la verdad. Como sostienen Davidson y Putnam, en contextos distintos y con fines distintos, tiene pleno sentido incrementar nuestra confianza en nuestras creencias a medida que se produce una mejora en nuestras normas de justificación, en nuestros cálculos y en la forma en que exhumamos experimentalmente nuevas observaciones 39 .

La diferencia fundamental cuando hemos llegado a este punto entre Rorty y un "platónico" es que Rorty no ve ningún motivo para considerar la nueva teoría como mejor candidata a la verdad. Es cierto que Rorty sostiene que "la justificación ante más y más audiencias conduce a un riesgo cada vez menor de refutación y, así, a una cada vez menor necesidad de precaución [...] Pero solo se puede decir que tal justificación conduce a la verdad si se pudiera de alguna manera proyectar desde lo condicionado a lo incondicionado - desde todas las audiencias imaginables a todas las audiencias posibles"40. Pero ya he argumentado que esto no es así. Por el contrario, el platónico dice más bien lo siguiente. La justificación que, potenciada por métodos lógicos más refinados y afianzados así como por nuevos datos, observaciones y, donde sea posible, también por corroboraciones empíricas, ha servido para rechazar la teoría anterior y para proponer una nueva teoría y quizá incluso para plantear nuevas preguntas e introducir nuevos supuestos en la discusión, no condu-

39 Davidson (2000), p. 67; Putnam (1995), p. 69.

40 Rorty (2000a), p. 12. 
ce directamente al convencimiento evidente de que la teoría nueva es verdadera o aproximadamente verdadera o que conduzca a la verdad (el falibilismo, no el escepticismo, siempre está al acecho), pero sí a sostener racionalmente que es mejor candidata a la verdad y que, por tanto, conlleva un menor riesgo de refutación y un menor riesgo de que se haga efectiva para ella la glosa admonitoria “... y no ser verdad". Así, al menos, es de momento vivida y recibida en contextos de pensamiento y acción por quienes participan en la discusión. No declaramos su correspondencia sino su mayor verosimilitud en tanto que mejor disposición para ser candidata a la verdad. Es una verosimilitud que nos sirve de signo indicativo, en el sentido husserliano, de mayor afinidad cognitiva, cum fundamento in re, con la verdad y, así, con la realidad sin tener certeza de ello.

\subsection{De la verosimilitud a la posible verdad}

Una vez que se ha propuesto la nueva teoría, considerada como mejor pertrechada para ser candidata a la verdad y, por consiguiente, más difícil de descartar, en ese momento es racionalmente sensato, como dice Platón en Fedón dando un paso más allá de Gorgias, que el discurso se considere como verdadero. Y se puede considerar como verdadero en el siguiente sentido. La nueva creencia propuesta puede, desde luego, ser falible. Eso es lo que ha enseñado la experiencia pasada, la cual nos ha servido para comprender el sentido y posibilidad del error gracias al falibilismo asimétrico. Pero, ¿qué quiere decir aquí falibilidad y cuál es su sentido? Falibilidad quiere decir que una creencia que ha surgido de las cenizas de las creencias previas y a las que ya no se puede volver, pero que, sin embargo, puede ser considerada fiablemente como más verosímil, puede, no obstante, ser falsa. Por tanto, puede ser descartada en el futuro por una audiencia más competente y más equipada para juzgar sobre el asunto porque, por ejemplo, puede tener en cuenta nuevos hechos. Pero, ¿llegará semejante creencia a ser descartada de hecho? No necesariamente, diría la postura platónica. Por este motivo, como sostenía William James, tengo derecho a creer en ella no vaya a ser que por miedo a caer en el error, no consiga declarar una verdad. ${ }^{41} \mathrm{La}$ falibilidad es solo indicativa de una posibilidad que, sin embargo, no pertenece en sí a la creencia. La falibilidad es solo una sombra de preocupación, de peligro como dice Rorty, que algunos sujetos y comunidades proyectan sobre las creencias que ellos sostienen actualmente en virtud de sus experiencias de error pasadas ${ }^{42}$. Esta sombra de duda se transluce en la idea consensuada de que la creencia está bien justificada pero que podría no ser verdad. Sin embargo, habrá que esperar a ver qué sucede en el futuro para determinar si llegará a haber de hecho una

41 James (1896/1979), p. 30.

42 Rorty (2000a), p. 4. 
comunidad que se erija como aquella que elimine definitivamente a las creencias pasadas y vaya, por tanto, más allá de la sombra que generaciones anteriores habían proyectado sobre ellas a pesar de considerarlas más robustas que otras. En el primer caso, esta nueva generación considerará retrospectivamente que la sombra de duda que arrojó la audiencia pasada en virtud de su experiencia tiene ahora una razón de ser. Y si esta nueva generación no lo hace, cabe la posibilidad de que una futura lo haga. Sin embargo, es posible también que tal posibilidad no se cumpla ni con una generación ni con otra y esto no necesariamente respecto de nosotros mismos, que podemos estar equivocados en muchas cosas, sino respecto de alguna de esas generaciones futuras.

En el caso de que las creencias pasadas se refuten, se propondrán otras creencias que puedan resultar más verosímiles por estar mejor y más sutilmente justificadas y que arrastrarán un menor grado de falibilidad por ser mejores candidatas a la verdad. Y así, sucesivamente. Todo esto quiere decir que una creencia no tiene que ser necesariamente descartada en el futuro, no tiene por qué haber necesariamente una audiencia futura competente que la desbarate, aunque ahora (el ahora que sea, incluso uno futuro) no lo podamos saber con absoluta certeza y aunque, en virtud de nuestras experiencias fallidas pasadas, también arrojemos una sombra de duda sobre ella a la que llamamos genéricamente su falibilidad. Es falible, puede fallar, puede haber una audiencia futura que la desbarate, pero puede que no.

En términos actuales esto quiere decir que la legitimidad de la conclusión que se quiere extraer del argumento de la meta-inducción pesimista (toda creencia y toda teoría ha resultado hasta ahora ser falsa y, por tanto, no correrá mejor suerte ninguna de nuestras creencias y teorías) no está absolutamente garantizada, con ser muy fuerte ${ }^{43}$. Es una hipótesis que necesita ser corroborada constantemente. En este sentido me alineo con autores como Park para quien un estudio minucioso de la historia de la ciencia nos permite construir una inducción optimista que podría neutralizar el peso de la metainducción pesimista ${ }^{4}$. La idea sería que, aunque sea cierto que las teorías pasadas son falsas, de esta situación no se sigue inductivamente que todos los aspectos relevantes de nuestras teorías actuales también resultarán falsos. No se sigue porque nuestras teorías actuales son más exitosas (empíricamente, técnicamente, etc.) y tienen mejores "cualidades de nacimiento" (birth qualities) que las teorías pasadas 45 .

\footnotetext{
43 Desde que L. Laudan publicara el artículo “A Confutation of Scientific Realism” (Laudan 1981), la literatura sobre la validez y límites del argumento de la meta-inducción pesimista, aunque él no le diera este nombre, ha sido enorme.

44 Park (2011).

45 Por "cualidades de nacimiento" Park entiende algo similar a lo que he estado defendiendo: creencias que surgen de las cenizas de las creencias previas mediante la mejora de los métodos lógicos de investigación, uno de los cuales, el único en el que Park incide, es la forma en que una teoría encaja con las demás teorías con las que está interconectada.
} 
Por este motivo podemos no solo surcar la existencia embarcados en esa creencia, como decía Platón en Fedón ${ }^{46}$, introduciendo ya así un evidente cariz práctico a nuestras creencias, sino aceptarla como verdadera, más allá de considerarla bien justificada. Decir que todas nuestras creencias van a ser falsadas porque muchas de nuestras creencias pasadas lo han sido es hacer futurología sin certeza última. Lo esencial, por tanto, del modelo de Platón para el tema que nos ocupa es que el discurso hipotéticamente más fuerte y que incita en cada momento al acuerdo no forzado no solo es un medio para surcar la existencia con cierta firmeza a falta de un medio más estable 47 , sino que, como dice Quine, es un discurso que sirve de norma de facto para la investigación y para nuestra consideración racional de la realidad.

Quine indica en el capítulo primero de "Word and Object" que "poseemos y usamos nuestras creencias del momento, incluso en medio de todo nuestro filosofar, hasta que, por medio de lo que es vagamente llamado método científico, las cambiemos aquí y allí por algunas mejores. Dentro de nuestra doctrina en evolución permanente, podemos juzgar la verdad [...] sometida a corrección, pero esto va de suyo"48. Bilgrami, en su valiosa discusión con Rorty, interpreta este texto de Quine en el sentido de que, desde el punto de vista de la comunidad de investigadores, nuestras creencias presentes robustamente justificadas de acuerdo con nuestros estándares se ponen en uso en la investigación para establecer los cánones de lo que puede y no puede ser tomado por verdad 49 . Levantando la limitación impuesta por la apelación de Quine al método científico, creo que es exactamente lo mismo, como puede verse, que lo que Platón decía ya en Fedón: tomar el discurso más inconmovible como verdadero. Por supuesto, el sentido que dan Platón y Quine a esta tesis es muy distinto, dados los contextos y los horizontes filosóficos y culturales tan dispares en que se inserta, pero su formulación desnuda es idéntica.

Por consiguiente, en cuanto al significado genérico de los acuerdos, resulta que no los buscaríamos sin poner en el horizonte de todos ellos, en el télos racional que los anima, la esperanza bien fundada de que en muchas ocasiones se cumplirán dos vertientes que tiene la investigación racional, a saber, la esperanza de que hemos extirpado una falsedad y, quizá por añadidura, la esperanza de que hemos atinado a decir también algo verdadero o, al menos, más plausiblemente verdadero, sin saberlo con certeza, lo que, debido al falibilismo, impide siempre hablar de que un enunciado es aproximadamente verdadero, aunque sí más verosímil.

Como sostiene Isaac Levi, es cierto que la adopción de una creencia como verdadera requiere siempre que el sujeto o la comunidad lleven a cabo algún tipo de cálculo costo-beneficio, ya que al incorporar una nueva creencia nos arriesgamos a

\footnotetext{
46 Platón (1986), Fedón 85c-d.

47 Platón (1986), Fedón 85c-d.

48 Quine (1960), pp. 24-25.

49 Bilgrami (2000), p. 250.
} 
importar nuevas falsedades en nuestro corpus epistémico, posibilidad que el modelo que propongo acepta con creces 50 . La situación puede ser asimilada, entonces, a un caso de decisión bajo riesgo. Como hemos visto, frente a esta estrategia estaría la de autores como Richard Boyd quien intenta usar argumentos abductivos del tipo "inferencia a la mejor explicación" de manera más acrítica para concluir sin más que nuestras mejores teorías actuales son aproximadamente verdaderas. Pero entre unos y otro, el modelo que planteo sugiere una fórmula intermedia. En este modelo el cálculo costo-beneficio en condiciones de riesgo ya está hecho dado que entraña más beneficio epistémico el liberarse de creencias que ahora nos parecen injustificables que mantenerlas. Además en esa maniobra se instaura una referencia a la realidad como a aquello a lo que no se ajusta la creencia eliminada y, por eso, se elimina. En cuanto al coste de poder introducir nuevas creencias que resulten a la postre también injustificables y falsas en un futuro más o menos próximo, como nos parecen a nosotros ahora las que ya hemos eliminado, es un coste que, por una parte, queda compensado por el beneficio precedente de eliminar creencias que están a nuestras luces injustificadas y, por otra, es racionalmente asumible porque, como he argumentado, aunque pueda haber una audiencia futura que desbarate algunas o muchas de nuestras creencias actuales, queda también la posibilidad abierta, a pesar de la fuerza indudable del argumento de la meta-inducción pesimista, no absolutamente probatoria, de que no la haya, además de haber mejorado nuestras formas lógicas de establecer creencias. Por tanto, siempre comporta un riesgo epistémico la adopción de la nueva creencia, bajo las estrictas condiciones establecidas, pero también abre un futuro esperanzado porque ese futuro o bien nos lleva a revisiones racionales de nuestras creencias que proporcionarán creencias más robustas por estar justificadas con métodos mejorados, o bien a creencias que queden indeterminadas respecto de su potencial para ser refutadas por audiencias futuras cognitivamente mejor pertrechadas e informadas, que quizá no lleguen a existir respecto de esa creencia, un beneficio siempre estimable y valorable racionalmente.

\section{Rorty: el acuerdo como sinécdoque}

Es hora de replegar velas después de haber propuesto una concepción diferente a la de Rorty sobre las relaciones entre justificación y verdad. Mi tesis en esta última sección es que, a la luz de los argumentos previos sobre cómo es mejor pensar estas relaciones, podemos considerar la concepción rortyana del acuerdo como un caso particular de sinécdoque pero en el que quien usa este tropo literario ha perdido ya completamente la capacidad de verlo como tal y lo toma literalmente produ-

50 Levi (1991), p. 4. 
ciendo una visión distorsionada de la realidad, en este caso, de la realidad del acuerdo y de su posible significado. Cuando se pierde esta capacidad, estamos ante un claro ejemplo de reduccionismo.

La sinécdoque es un caso de metonimia en el que se usa una parte de algo para hablar y representar el todo. En el caso de Rorty, es sinécdoque, es decir, es tomar la parte por el todo, considerar el acuerdo como mera coherencia etnocéntrica tanto en los juicios dentro de una tradición y una comunidad lingüística que son contingentes como en los procedimientos lógicos contingentes de justificación de las creencias, de tal manera que no tenga cabida el intentar considerar que un acuerdo así pueda tener ningún entronque o conectividad con la realidad, con un mundo que no está en mezcolanza con nuestro sistema de creencias. Para Rorty, los acuerdos solo producen interpretaciones etnocéntricas. Forma también parte fundamental de esta concepción del acuerdo el considerarlo como aquello que permite adoptar una disposición abierta, democrática e "inclusivista" para buscar acólitos, de maneras no forzadas y democráticas, en públicos que son más amplios que aquel que integra la comunidad originaria de justificación que ha llegado a un acuerdo significativo. Pero que se logre esta inclusividad tampoco quiere decir en Rorty nada acerca de si el acuerdo está fundado en su capacidad para desterrar la ignorancia y el error o, incluso, en su simultáneo potencial para expresar una verdad y, en cualquier caso, para estar mejor equipados de cara a futuras justificaciones respecto de las cuales detectar un error resulta más complejo.

Para mí, esta concepción es una sinécdoque reductivista porque es cierto que el acuerdo es una armonía en los juicios de una comunidad lingüística y en las formas de justificarlos, al igual que también es cierto que quienes acuerdan algo pueden después ponerse a la tarea de intentar, por medios pacíficos y democráticos, que otros acuerden con ellos lo mismo como fruto de la argumentación y la observación. El reductivismo, es decir, el perder de vista que este modelo del acuerdo es una sinécdoque, es precisamente pararse aquí, en la parte, y creer que decir esto agota en su totalidad lo que es un acuerdo y cuáles son sus rendimientos epistemológicos y ontológicos posibles. El problema es que el hecho de que un ethnos consiga pacífica y argumentativamente su objetivo expansionista no quiere decir nunca algo semejante a una esperanza racional de haber alcanzado en ningún caso una verdad o, al menos, de haber extirpado una falsedad para ningún ámbito de la experiencia humana, además del consiguiente aumento o incremento en la confianza racional en nuestras creencias, como decían Davidson y Putnam. El acuerdo en Rorty no permite, ni directa ni indirectamente, entroncar o enlazar las creencias acordadas con el mundo causal independiente de los sujetos sino solo con una interpretación, es decir, con una comunidad lingüística de comunicación siempre ampliable y condicionada por su propia historia contingente. Pero si el acuerdo puede tener esta función de poder llegar a remitir a algo distinto de sí mismo y de las creencias del grupo que lo ha adoptado, aunque con todas las limitaciones platónicas, humanas, 
que he señalado, entonces, como le dijo tantas veces Habermas a Rorty, podría haber una explicación plausible de por qué la justificación de un juicio que ha sido exitosa en nuestro contexto lingüístico y cultural podría hablar a favor de la verdad irrestricta de tal juicio de forma que esa verdad sea independiente del contexto donde surgió la proposición justificada ${ }^{51}$. Que en nuestra historia se haya asentado la creencia de que la Tierra gira alrededor del Sol no quiere decir necesariamente que cuando pensamos en el mundo de esta manera lo hacemos siempre interpretativa y etnocéntricamente.

En definitiva, el modelo platónico del consenso sirve para hacer ver que la dicotomía Rorty/Habermas, contextualismo/universalismo es una mala dicotomía pues el ser humano es un ser intermedio (tá metaxú), como también decía Platón ${ }^{52}$, que no puede tener nunca $\mathrm{o}$, al menos, para un número enorme de creencias, el convencimiento pleno de ser un habitante completo ni del mundo del "contexto" ni del mundo "universalista". Su creencia de que está en alguno de los dos como consecuencia de los consensos en los que participa no puede ser plenamente verificada en individuos como nosotros sin extralimitarse en sus capacidades. Este es un cierto tipo de agnosticismo cognitivo que es benigno e incluso racionalmente saludable. Aspira tanto al mundo "universalista", al que quizás está en vías de visitar, y aun lo haya hecho ya en algunas ocasiones, como no puede saber plenamente si ha salido efectivamente del otro, del mundo del "contexto", de la justificación etnocéntrica. Ni dogmatismo ni relativismo ni etnocentrismo. Por tanto, la postura de Platón, en general, es la que después ensayó Kant, en particular, para la ética. No se puede saber con plena certeza si uno se ha hecho moralmente bueno cuando ha realizado una acción que es, por lo demás, conforme al deber, pero es posible que sí se haya hecho moralmente bueno haciéndola. No se puede saber con plena certeza si uno ha emitido un juicio con carácter universal (la Tierra gira alrededor del Sol) cuando se atiene a la legalidad de los métodos de razonamiento y justificación que se han ido depurando en el proceso de la discusión, pero es posible -y mucho en muchos casos- que sí lo haya hecho, aunque no lo pueda aseverar a ciencia cierta en el momento presente.

\section{Referencias bibliográficas}

Bilgrami, A. (2000): "Is Truth a Goal of Inquiry? Rorty and Davidson on Truth", en Robert B. Brandom (ed.), Rorty and His Critics, Malden, Mass., Blackwell, pp. 242-262.

BoyD, R. (1990): "Realism, Approximate Truth, and Philosophical Method", en

\footnotetext{
51 Habermas (2000), p. 42.

52 Platón (1981), Lisis 216c-e; Platón (1986), Banquete 202a.
} 
C.W. Savage (ed.), Minnesota Studies in the Philosophy of Science, 14, Minnesota, University of Minnesota Press, pp. 355-391.

Davidson, D. (2000): “Truth Rehabilitated”, en Robert B. Brandom (ed.), ob.cit., pp. 65-74.

Habermas, J. (1999): Wahrheit und Rechtfertigung, Frankfurt am Main, Suhrkamp. Habermas, J. (2000): "Richard Rorty's Pragmatic Turn", en Robert B. Brandom (ed.), ob.cit., pp. 31-55.

Hurtado, G. (2009): Por qué no soy falibilista y otros ensayos filosóficos, Matamoros, México, Los Libros de Homero.

Husserl, E. (1900/1984): Logische Urtersuchungen. Hua XIX/1, Ursula Panzer (ed.), La Haya, Martinus Nijhoff.

James, W. (1896/1979): “The Will to Believe", en The Works of William James. The Will to Believe and Other Essays in Popular Philosophy, Cambridge, Mass., Harvard University Press, pp. 13-33.

James, W. (1907/1975): Pragmatism and the Meaning of Truth, Cambridge, Mass., Harvard University Press.

KALPOKAS, D. (2005): Richard Rorty y la superación pragmatista de la filosofia, Buenos Aires, Del Signo.

Laudan, L. (1981): "Confutation of Convergent Realism", Philosophy of Science, 48, pp. 19-49.

Levi, I. (1991): The Fixation of Belief and Its Undoing. Changing Beliefs Through Inquiry, Cambridge, Cambridge University Press.

McDowell, J. (2000): “Towards Rehabilitating Objectivity", Robert B. Brandom (ed.), ob.cit., pp. 109-123.

NiInILuoto, I. (1999): Critical Scientific Realism, Oxford, Oxford University Press. NiINILUOTO, I. (1987): Truthlikeness, Dordrecht, D. Reidel.

OdDie, G. (1986): Likeness to Truth, Dordrecht, D. Reidel.

PARK, S. (2011): "A Confutation of Pessimistic Induction", Journal of General Philosophy of Science, 42.1, pp. 75-84.

PeIrCE, Ch. S. (1877/1974): “The Fixation of Belief”, Collected Papers of Charles Sanders Peirce, Vol V, Charles Hartshorne y Paul Weiss (eds.), Cambridge, Mass., Harvard University Press, pp. 223-247.

PeredA, C. (1999): Crítica de la razón arrogante. Cuatro panfletos civiles, México, Taurus-Alfaguara.

Platón, (1981): Apología, Lisis, en Diálogos, Vol. I, J. Calonge Ruiz y E. Lledó Íñigo (trads.), Madrid, Gredos.

Platón, (1983): Gorgias, en Diálogos, Vol. II, J. Calonge Ruiz (trad.), Madrid, Gredos.

Platón, (1986): Fedón, Banquete, en Diálogos, Vol. III, Carlos García Gual y M. Martínez Hernández (trads.), Madrid, Gredos. (He seguido esta traducción con algunas modificaciones.) 
Platón, (1992): Filebo, en Diálogos, Vol. VI, María Ángeles Durán (trad.), Madrid, Gredos.

Putnam, H. (1995): Pragmatism. An Open Question, Oxford, Blackwell.

Quine, W.V.O. (1960): Word and Object, Cambridge, Mass., The M.I.T. Press.

Rorty, R. (1989): Contingency, Irony, and Solidarity, Cambridge, Cambridge University Press.

RoRTy, R. (1991a): "Solidarity or Objectivity", en Objectivity, Relativism, and Truth. Philosophical Papers, Vol.1, Cambridge, Cambridge University Press, pp. 21-34.

RoRTY, R. (1991b): "Science as Solidarity", en Objectivity, Relativism, and Truth. Philosophical Papers, Vol.1, ed.cit., pp. 35-45.

RoRTY, R. (1991c): "Inquiry as Recontextualization: An Anti-dualist Account of Interpretation", en Objectivity, Relativism, and Truth. Philosophical Papers, Vol.1, ed.cit., pp. 93-110.

RORTY, R. (1991d): "Pragmatism, Davidson and Truth", en Objectivity, Relativism, and Truth. Philosophical Papers, Vol.1, ed.cit., pp. 126-150.

RoRTY, R. (1993): "Putnam and the Relativist Menace", The Journal of Philosophy, XC, $n^{\circ} .9$, pp. 443-461.

RORTY, R. (1995): "Is Truth a Goal of Inquiry? Davidson vs. Wright", The Philosophical Quarterly, 45, pp. 281-300.

RoRTY, R. (1998): “Charles Taylor on Truth", en Truth and Progress. Philosophical Papers, Vol. 3, Cambridge, Cambridge University Press, pp. 84-97.

Rorty, R. (1999): Philosophy and Social Hope, Londres, Penguin.

RORTY, R. (2000a): “Universality and Truth”, en Robert B. Brandom (ed.), ob.cit., pp 1-30.

RoRTY, R. (2000b): “Response to McDowell”, en Robert B. Brandom (ed.), ob.cit., pp 123-128.

TAYlOR, Ch. (1990): "Rorty in the Epistemological Tradition", en Alan R. Malachowski (ed.), Reading Rorty. Critical Responses to Philosophy and the Mirror of Nature (and Beyond), Oxford, Blackwell, pp. 257-275.

Wellmer, A. (2010): "Rorty on Truth, Justification, and Experience", en Randall E. Auxier y Lewis Edwin Hahn (eds.), The Philosophy of Richard Rorty, The Library of Living Philosophers, XXXII, Chicago, Open Court, pp. 313-342.

Wittgenstein, L. (1969): On Certainty. Über Gewissheit, Basil Blackwell, Oxford.

Óscar L. González-Castán

Dpto. de Filosofía Teorética

Facultad de Filosofía

Universidad Complutense de Madrid

oscar.gonzalez@ucm.es 